\title{
SPECTROSCOPIC AND VOLUMETRIC TECHNIQUES FOR THE ESTIMATION OF IVABRADINE IMPURITY 3,3'-(PROPANE-1,3-DIYL)BIS(7,8-DIMETHOXY-1,3,4,5-TETRAHYDRO-2H- BENZO[D]AZEPIN-2-ONE)
}

\section{S. ANIL KUMAR, B. L. BHASKAR*}

Department of Chemistry, Amrita School of Engineering, Bengaluru, Amrita Vishwa Vidyapeetham, India Email: bl_bhaskar@blr.amrita.edu

Received: 09 Jan 2019, Revised and Accepted: 18 Mar 2019

\section{ABSTRACT}

Objective: Two simple and sensitive techniques-one spectrophotometric and one titrimetric-have been developed for the determination of 3,3'(propane-1,3-diyl)bis(7,8-dimethoxy-1,3,4,5-tetrahydro-2H-benzo[d]azepin-2-one) commonly known as ivabradine impurity-9 (IVA-9).

Methods: The spectrophotometric method is based on the oxidation of drug impurity by excess cerium (IV) sulphate in acidic medium and the subsequent reaction of the remaining Ce(IV) with a known amount of ferrous ammonium sulphate. The resultant ferric ion is then made to react with thiocyanate in acid medium to form a brown coloured complex which is analyzed spectrophotometrically against the reagent blank. In the volumetric method, the un-reacted Ce(IV) is titrated against standard ferrous ammonium sulphate to estimate the quantity of IVA-9.

Results: The colored complex showed an absorption maximum at $479 \mathrm{~nm}$ when measured spectrophotometrically. The stated methods are validated statistically using the International Council for Harmonization guidelines-ICH Q2(R1) for precision and accuracy. The method showed a linear response from 0.5 to $100 \mu \mathrm{g} / \mathrm{ml}$ with a correlation coefficient of 0.9985 .

Conclusion: No estimation techniques have been reported to date for the determination of this molecule. The proposed techniques may be used for the routine quantification in its pure form and also in the presence of its parent drug molecule Ivabradine.

Keywords: Ivabradine impurity-7, Ce(IV), UV-Visible spectrophotometry, Drug impurity

(C) 2019 The Authors. Published by Innovare Academic Sciences Pvt Ltd. This is an open-access article under the CC BY license (http://creativecommons.org/licenses/by/4.0/) DOI: http://dx.doi.org/10.22159/ijap.2019v11i3.31953

\section{INTRODUCTION}

3,3'-(propane-1,3-diyl)bis(7,8-dimethoxy-1,3,4,5-tetrahydro-2Hbenzo[d]azepin-2-one) (IVA-9) is a pharmaceutical impurity formed en route the synthesis of anti-ischaemic drug ivabradine. Ivabradine is a cardiotonic agent used to treat suggestive chronic heart failures which are not managed by beta blockers. It's efficiency in treating angina pectoris and myocardial ischemia, without any negative hemodynamic effects, has been described [1]. Estimation of ivabradine has been achieved in the past by high-performance liquid chromatography [2-4], thin layer chromatography [5-8], liquid chromatography with spectrometry [9-11] and spectrophotometry $[12,13]$. The polymorphism, co-crystallization [14], crystal chemistry [15] and sustained release studies [16] of ivabradine were reported. Xray analysis and conformational studies [17] showed the chlorine salt of ivabradine as a horseshoe-shaped diastereomer with two asymmetric bicyclic moieties. The first part is made up of a sevenmembered lactam structure and the second part contains a fourmembered ring. The structure and properties of IVA-9 are expected to be significantly different from that of ivabradine as it is made up of two symmetric benzazepine units connected via aliphatic acyclic linkage and lacking tertiary amino nitrogen as seen in fig. 1(a) and 1(b).

The structural and chemical properties of drug molecules and their intermediates play a big role in pharmacokinetics and drug action. As IVA-9 is an intermediate impurity of drug ivabradine, we tried to explore the molecule. However, the perusal of literature revealed a dearth of details regarding the structure and property of this molecule. Though the spectrophotometric estimation of ivabradine in the presence of its degradation products has been described by Mostafa $e t$ al. [18], the structural properties of the title molecule were unexplored. Further, no estimation techniques have been reported so far to determine IVA-9 in its pure form or as a pharmaceutical intermediate. The authors have performed similar studies in the past on 4-nitro 2-phenoxy aniline using 8-hydroxyquinoline which is an impurity associated with the drug nimesulide $[19,20]$. As an extension study, we propose one spectrophotometric method and one volumetric method for the determination of IVA-9 in the pure form also in the presence of its parent drug molecule ivabradine.



Fig. 1(a): Structure of IVA-9<smiles>COc1cc2c(cc1OC)CC(=O)N(CCCN(C)C[C@H]1Cc3cc(OC)c(OC)cc31)CC2</smiles>

Fig. 1(b): Structure of ivabradine

The proposed methods involve the oxidation of IVA-9 by a surplus amount of $\mathrm{Ce}(\mathrm{IV})$ and the subsequent reaction of the remaining Ce(IV) with a known amount of ferrous ammonium sulphate. The resultant ferric ion is then made to react with thiocyanate in an acid medium to form a brown colour complex [21].

\section{Reaction Scheme \\ Drug $+\mathrm{Ce}(\mathrm{IV}) \rightarrow$ Oxidized form of drug+Ce(III) \\ Excess $\mathrm{Ce}(\mathrm{IV})+\mathrm{Fe}^{+2} \rightarrow \mathrm{Ce}(\mathrm{III})+\mathrm{Fe}^{+3}$ \\ $\mathrm{Fe}^{+3}+\mathrm{SCN} \rightarrow$ Complex}

Optimum reagent and reaction conditions were arrived at by fixing the concentration of one reagent while varying others. Ideal reagent concentrations and sequence of addition are listed below. 
Different aliquots of reagent stock were mixed with $1 \mathrm{ml}$ of $5 \mathrm{M}$ hydrochloric acid and $3 \mathrm{ml}$ of Ce(IV) sulpahate $(400 \mu \mathrm{g} / \mathrm{ml})$ and allowed to stand for $15 \mathrm{~min}$. To this $2 \mathrm{ml}$ of ferrous ammonium sulphate $(300 \mu \mathrm{g} / \mathrm{ml})$ was added and after $5 \mathrm{~min}, 1 \mathrm{ml}$ of $30 \%$ potassium thiocyanate was added and mixed well. The solution was then made up using double distilled water and analyzed spectrophotometrically. The absorption maximum was recorded at $479 \mathrm{~nm}$ against the reagent blank (fig. 2).

The listed methods are validated statistically using ICH Q2(R1) guidelines[22]. The precision and accuracy of the method were ascertained by both intraday and interday recovery studies and given in table 1.

The sensitivity of the method is apparent from various regression parameters such as sandell sensitivity, molar absorptivity, limit of detection, limit of quantification etc. and demonstrated in table 2.

Under the listed optimum conditions, a linear response has been observed between absorbance and concentration of drug impurity over a wide range (fig. 3 ).

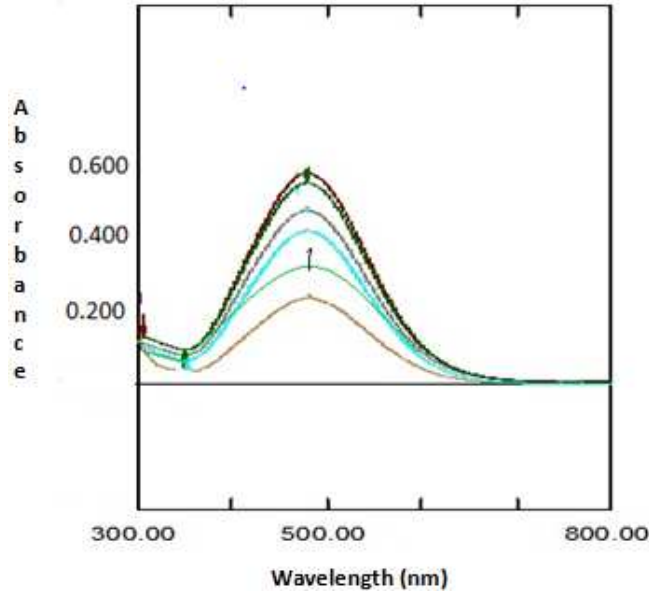

Fig. 2: Absorption maximum at $479 \mathrm{~nm}$

Table 1: Recovery studies

\begin{tabular}{|c|c|c|c|c|c|c|c|}
\hline \multirow{2}{*}{ Technique } & \multirow[t]{2}{*}{ Iva-9 added } & \multicolumn{3}{|c|}{ Intra-day assessment } & \multicolumn{3}{|c|}{ Inter-day assessment } \\
\hline & & Iva-9 obtained & \% RE & \% RSD & Iva-9 obtained & \% RE & \% RSD \\
\hline \multirow{3}{*}{$\begin{array}{l}\text { Spectrophotometry } \\
(\mu \mathrm{g} / \mathrm{ml})\end{array}$} & 1.0 & 1.02 & 2.00 & 2.58 & 0.98 & 2.00 & 2.85 \\
\hline & 2.0 & 2.03 & 1.50 & 1.05 & 1.98 & 1.00 & 1.33 \\
\hline & 3.0 & 3.03 & 1.00 & 0.87 & 2.95 & 1.67 & 1.80 \\
\hline \multirow{3}{*}{$\begin{array}{l}\text { Titration } \\
\text { (mg) }\end{array}$} & 2.0 & 2.02 & 1.00 & 0.98 & 1.95 & 2.50 & 2.80 \\
\hline & 4.0 & 4.04 & 1.00 & 1.33 & 3.94 & 1.50 & 1.80 \\
\hline & 6.0 & 6.03 & 0.50 & 0.55 & 5.92 & 1.33 & 2.20 \\
\hline
\end{tabular}

Table 2: Regression parameters

\begin{tabular}{ll}
\hline Parameter & Range \\
\hline$\lambda_{\text {Max }}$ nm & $479 \mathrm{~nm}$ \\
Beer's Law range, $\mu \mathrm{g} / \mathrm{ml}$ & $0.5-100 \mathrm{mg} / \mathrm{l}$ \\
Molar absorptivity, $\mathrm{L} \mathrm{mol}^{-1} \mathrm{~cm}^{-1}$ & $1.86062 \times 10^{5}$ \\
Limit of detection, $\mu \mathrm{g} / \mathrm{ml}$ & 0.14 \\
Limit of quantification, $\mu \mathrm{g} / \mathrm{ml}$ & 0.42 \\
Sandell sensitivity & 0.0027 \\
Regression Equation* & \\
Intercept & 0.6136 \\
Slope & -0.0512 \\
$\mathrm{~S}_{\mathrm{a}}$ & 0.0094 \\
$\mathrm{~S}_{\mathrm{b}}$ & 0.0014 \\
Correlation Coefficient & -0.99848 \\
\hline
\end{tabular}

* $\mathrm{Y}=\mathrm{a}+\mathrm{bX}$, where $\mathrm{Y}$ is absorbance and $\mathrm{X}$ is concentration $(\mu \mathrm{g} / \mathrm{ml}), \mathrm{S}_{\mathrm{a}}=$ Standard deviation of intercept and $\mathrm{S}_{\mathrm{b}}=$ Standard deviation of the slope.



Fig. 3: Calibartion curve

For volumetric estimation, $10 \mathrm{ml}$ of $50 \mu \mathrm{g} / \mathrm{ml}$ equivalent of stock solution is mixed with $1 \mathrm{ml}$ of $1 \mathrm{M}$ sodium acetate and $5 \mathrm{ml}$ of $0.05 \mathrm{M}$ of Ce(IV) sulpahate. The contents were mixed throughly and made to stand for $15 \mathrm{~min}$. To this $5 \mathrm{ml}$ of $3 \mathrm{M}$ sulphuric acid solution was added and titrated against $0.05 \mathrm{M}$ ferrous ammonium sulphate using ferroin indicator. The experiment was repeated with a blank titration for comparison.

The reported methods are free from cumbersome extraction steps. Since no estimation techniques have been reported till date, the authors are hopeful that the proposed methods could be used for the determination of IVA-9 in the pure form and in pharmaceutical formulations. Further, there is scope to explore the said method as a marker test to find the presence 3,3'-(propane-1,3-diyl)bis(7,8dimethoxy-1,3,4,5-tetrahydro-2H-benzo[d]azepin-2-one) as an impurity in the parent drug ivabradine.

\section{AUTHORS CONTRIBUTIONS}

All the author have contributed equally

\section{CONFLICTS OF INTERESTS}

Declared none

\section{REFERENCES}

1. Riccioni G. Ivabradine: an intelligent drug for the treatment of ischemic heart disease. Molecules 2012;17:13592-604. 
2. Klippert $\mathrm{P}$, Jeanniot JP, Polve $\mathrm{S}$, Lefevre $\mathrm{C}$, Merdjan $\mathrm{H}$. Determination of ivabradine and its $\mathrm{N}$-demethylated metabolite in human plasma and urine, and in rat and dog plasma by a validated high-performance liquid chromatographic method with fluorescence detection. J Chromatogr B Biomed Sci Appl 1998;719:125-33.

3. François Bouchard M, Simonin G, Bossant MJ, Boursier Neyret C. Simultaneous determination of ivabradine and its metabolites in human plasma by liquid chromatographytandem mass spectrometry. J Chromatogr B Biomed Sci Appl 2000;745:261-9.

4. Maheshwari S, Khandhar AP, Jain A. Quantitative determination and validation of ivabradine HCL by a stability indicating RPHPLC method and spectrophotometric method in solid dosage form. Eurasian J Anal Chem 2010;5:53-62.

5. Motisariya MH, Patel KG, Shah PA. Validated stability-indicating high-performance thin layer chromatographic method for determination of ivabradine hydrochloride in bulk and marketed formulation: an application to kinetic study. Bull Fac Pharm (Cairo Univ) 2013;51:233-41.

6. Pikul P, Nowakowska J, Ciura K. Chromatographic analysis of ivabradine on polar, nonpolar and chemically modified adsorbents by HPTLC. J Food Drug Anal 2013;21:165-8.

7. Pikul P, Nowakowska J, Ciura K. Effect of non-aqueous and buffered mobile phase composition on the retention of ivabradine. J Liq Chromatogr Relat Technol 2014;37:1837-46.

8. Damle M, Bagwe R. Development and validation of stabilityindicating HPTLC method for ivabradine HCl. Pharma Sci Monit 2015;6:141-52.

9. Jin X, Lu CT, Feng Yl, Ding LK, Guan Y, Sun W, et al. Determination of ivabradine in human plasma by LC-MS/MS and study of pharmacokinetics. Prog Mod Biomed 2011;14:4.

10. Lu C, Jia Y, Yang J, Jin X, Song Y, Liu W, et al. Simultaneous determination of ivabradine and $\mathrm{N}$-desmethyllvabradine in human plasma and urine using a LC-MS/MS method: application to a pharmacokinetic study. Acta Pharm Sin B 2012;2:205-12.

11. Jiang J, Tian L, Huang Y, Li Y. Development and validation of a sensitive LCMS/MS ESI method for the determination of ivabradine in human plasma: application to a pharmacokinetic study. Biomed Chromatogr 2013;27:1603-8.
12. Panda S, Patra S. Rapid and selective UV spectrophotometric and RP-HPLC methods for dissolution studies of ivabradine controlled-release formulations. PharmaTutor 2014;2:201-3.

13. Bhosale SD, Vanjari SS, Nikhil SJ. Development of stability indicating a spectrophotometric method for the estimation of Ivabradine hydrochloride in bulk and in tablet formulation. World J Pharm Pharm Sci 2016;5:1919-27.

14. Sládkova V, Dammer O, Sedmak G, Skorepova E, Kratochvil B. Ivabradine hdrochloride (S)-mandelic acid co-crystal: In situ preparation during formulation. Crystals 2017;7:13.

15. Masciocchi N, Aulisio A, Bertolini G, Sada M, Garis F, Malpezzi L. Disclosing the extensive crystal chemistry of ivabradine hydrochloride in its pure and solvated phases. Powder Diffr 2013;28:200-6.

16. Kothiya OM, Patel BA, Patel KN, Patel MM. Formulation and characterization of sustained release matrix tablets of ivabradine using full factorial design. Int J Appl Pharm 2018;10:59-66.

17. Duval D, Hennig P, Bouchet JP, Vian J, Peglion JL, Volland JP, et al. Stereochemical study of a bradicardisant benzazepine type drug-X-ray structure of the chloride salt and high field NMR study of the stereochemistry in solution. Magn Reson Chem 1997;35:175-83.

18. Mostafa NM, Fayez YM, Farid JF, El-Alim AEB. Stability indicating spectrophotometric methods for determination of ivabradine hydrochloride in the presence of its degradation product. Anal Chem Lett 2018;7:280-94.

19. Kumar SA, Bhaskar BL. Spectrophotometric evaluation of nimesulide impurity D: 4-nitro-2-phenoxyaniline using 8hydroxyquinoline as an oxidative coupling reagent. Asian J Pharm Clin Res 2017;10:204-6.

20. Kumar SA, Bhaskar BL. Computational and spectral studies of nimesulide impurity D: 4-nitro 2-phenoxy aniline. Asian J Chem 2015;27:3907-12.

21. Devi OS, Basavaiah K, Revanasiddappa HD, Vinay KB. Titrimetric and spectrophotometric assay of pantoprazole in pharmaceuticals using cerium (IV) sulphate as oxidometric agent. J Anal Chem 2011;66:490-5.

22. Int Conf on Harmonization of technical requirements for registration of pharmaceuticals for human use, ICH Harmonized Tripartite Guideline Validation of Analytical Procedures: Text and Methodology Q2(R1), London; 2005. 